\title{
A National Web Conference on Integrated Siddha Approach in Clinical Practice and Research on COVID-19 Pandemic (ISACC)- Tirupati, December 2020
}

\author{
K. Samraj ${ }^{1 *}$, K. Nandhagopal' ${ }^{1}$, S. Radha ${ }^{1}$, S. Rajalakshmi ${ }^{1}$, K. Arunachalam ${ }^{1}$ and K. Kanakavalli ${ }^{2}$ \\ 'Siddha Clinical Research Unit, Central Council for Research in Siddha, Tirupati - 517507, Andhra Pradesh, \\ India; samraj.mailme@gmail.com \\ ${ }^{2}$ Central Council for Research in Siddha, Chennai - 600106, Tamil Nadu, India
}

\begin{abstract}
Siddha Clinical Research Unit (SCRU) Tirupati, working under the Central Council for Research in Siddha (CCRS), Ministry of AYUSH, Govt. of India, conducted a National Web conference titled "Integrated Siddha Approach in Clinical Practice and Research on COVID-19 Pandemic (ISACC)" on 23 $3^{\text {rd }}$ Dec 2020, as a part of the fourth Pre-Siddha Day observance. Totally, 256 participants from Siddha colleges and various institutes of CCRS attended the Web conference and 9 eminent Speakers share their knowledge at the conference. The Technical session was separated by three panels, (i)Siddha Standalone and Integrative Clinical trials on COVID-19, (ii)Siddha Preventive and Prophylactic Measures on COVID-19, (iii)Experiences in Siddha Integrative Clinical Practice on COVID-19. The take home message of the conference insisted upon the three facts - the need for more clinical trials , need for increased experience sharing platforms for Siddha medical system and finally that Siddha standalone as well as integration for COVID-19 management gave significant outcome in both preventive and promotive healthcare. Central Council for Research in Siddha (CCRS), Ministry of AYUSH, Govt. of India and Directorate of Indian Medicine and Homeopathy (DIM\&H), Government of Tamil Nadu, contributed a lot in Research and services in COVID-19 pandemic.
\end{abstract}

Keywords: Siddha Medicine, Integrative Medicine, COVID-19, CCRS, $4^{\text {th }}$ Siddha Day

\section{Introduction}

Siddha Clinical Research Unit (SCRU) Tirupati, working under the Central Council for Research in Siddha (CCRS), Ministry of AYUSH, Govt. of India, conducted a National Web conference titled "Integrated Siddha Approach in Clinical Practice and Research on COVID-19 Pandemic (ISACC)" on $23^{\text {rd }}$ Dec 2020, as a part of the fourth PreSiddha Day observance. Totally, 256 participants from Siddha colleges and various institutes of CCRS attended the Web conference and 9 eminent Speakers shared their knowledge at the conference.

The COVID-19 pandemic is considered a lifethreatening disease due to the lack of appropriate drug or vaccine till December 2020, which has caused the world to turn towards traditional medicine. Traditional medicine in India such as Siddha, Ayurveda, and Yoga played a critical role in COVID-19 pandemic management. This web conference is aimed to highlight synopsis and explore the Siddha drugs used as well as to rationalize its scientific evidence to the globe. The event began with the Inaugural Address by Prof. Dr. K. Kanakavalli, Director General, CCRS, Ministry of AYUSH, Govt. of India. The Special Address was given by Prof. Dr. P. Parthiban, Joint Director, Directorate of Indian Medicine and Homeopathy (DIM\&H), Tamil Nadu. The special invitees Prof. Dr. K. Balagurusamy, Principal from Velumailu Siddha Medical College and Hospital, Tamil Nadu, Prof. Dr. K. Thangadurai, Principal of JSA Medical College for Siddha and Research Centre, Tamil Nadu and

${ }^{*}$ Author for correspondence

Article Received on: 09.03.2021

Revised on: 22.05.2021

Accepted on: 22.05.2021 
Dr. P. Sathiyarajeswaran, Director, Scientist-III, Incharge, Siddha Central Research Institute, CCRS, Chennai, Tamil Nadu also addressed the meeting. The Technical session was headed by three panels,

1. Siddha Standalone and Integrative Clinical trials on COVID-19

2. Siddha Preventive and Prophylactic Measures on COVID-19

3. Experiences in Siddha Integrative Clinical Practice on COVID-19

\section{Summary of the Presentations}

Anurag Srivastava, M.D, HOD, Department of Community medicine, Government institute of medical sciences (GIMS), Noida, India,

Anurag explained the clinical trial titled "A double blinded Comparative RCT to evaluate the effectiveness of siddha medicines, Kabasura kudineer (KSK) and Nilavembu Kudineer (NVK) along with Standard allopathy treatment in symptomatic COVID19 patients", which was conducted in Government Institute of Medical Sciences (GIMS) in collaboration with CCRS. He explained the primary objective of the trial as to explore the effectiveness of standard care along with KSK and NVK in the reduction of the viral load in clinical symptoms like fever, Cough, dyspnea. Reduction in the risk of disease progression, duration of hospital stays, exploring the Siddha body constitution of COVID-19 patients, monitoring of ADR/AE are another secondary objective. He explained the selection criteria as mild to moderate COVID-19 positive cases been included in the trial and patients with Chronic Renal Failure, uncontrolled diabetes, severe hypertension and malignancies been excluded from the trial. Further, he explained about the intervention arms, Arm I received Standard Allopathy intervention, placebo decoction alike trial drug, Arm II received Standard Allopathy intervention, NVK, Arm III received Standard Allopathy intervention, KSK.

Kannan Muthaiah, M.D(s), Scientist-II, HOD, Department of Technical and Literary Research and Documentation, Siddha Central Research institute, Chennai, India.

Kannan explained a clinical trial titled "A Prospective, non-randomized, Single-arm interventional study to assess the safety and efficacy of Siddha sasthric Medicine- Fixed Regimen in the prevention of COVID-19 disease progression of asymptomatic and mild category at Siddha COVID Care Centre (SSM-FiRe)", which was conducted in Stanley medical college, Chennai, India in Collaboration with CCRS, DIM\&H, The Indian Medical Practitioners Co-operative Pharmacy and stores (IMPCOPS) Ltd. He elaborated the rationale behind the study, also mentioned about the guidelines for Siddha practitioners for COVID-19 management published by CCRS, Ministry of AYUSH. He described the Primary Objective of the trial as preventing the disease progression, in asymptomatic, mild stage COVID patients. The Secondary objective is to determine the safety of the SSM- FiRe drugs, duration of hospital stay, exploring the Siddha body constitution of COVID-19 patients, monitoring of $\mathrm{ADR} / \mathrm{AE}$.

He further briefed that in the trial, as the sample size is 60 the selection criteria was that the RT-PCR positive COVID patients were included, COVID-19 positive with Severe symptoms, Patient with Chronic Renal Failure, Uncontrolled diabetes, Hemoglobin 7 and below, were excluded from the trial. He also shared some interesting results of the trial that, out of 60 participants, 50 participants turned negative on the $7^{\text {th }}$ day, 2 participants turned negative on the $10^{\text {th }}$ day, 7 participants turned negative on the $14^{\text {th }}$ day, 1 participant didn't turn negative even after the $14^{\text {th }}$ day. He said that as per the Siddha text, Aiyam constitution has stronger immunity; Azhal constitution has moderate immunity compared to Vali constitution, which correlated with the trial as 40 were of Azhal constitution, 14 were of Aiyam constitution, 5 were of Vali constitution. He also added that there was no ADR/AE reported throughout the trial.

The second panel discussion of the webinar was Siddha Preventive and Prophylactic Measures on COVID 19 under which the following topics were discussed. The session was chaired by Kannan Muthaiah.

Samraj K M.D(s), Research Officer (Siddha), Scientist-I and In-charge, Siddha Clinical Research Unit (CCRS) Tirupati, Andhra Pradesh.

Samraj explained about the "Role of Siddha medicines in Quarantine Centers /High Risk Population". He reviewed the concept of Preventive and Prophylactic Measures of COVID-19 in Siddha System through a different perspective. He made note of the strategy of the World Health Organization (WHO) and public health officials that insists on good nutrition, reduced stress and optimum physical activities to build general immunity to the public to challenge the COVID 19 pandemic. In his view he opined that boosting the immunity could be complemented preferring over traditional, Phytotherapeutic medicines and non-medicinal practices compared to other means. As said by Samraj, Siddha fundamentals state that Muththodam-Uyirthaadhu 
(3 Vital energy) comprises of Vali (or Vatham - Airy), Azhal (or Pitham - Fiery) and Aiyam (or Kabam- Watery/ Cool) are the three vital life forces that govern the physical, physiological and psychological components of an individual, framing the individual Udaliyal/ Yakkaillakkanam (YI), Body constitution. These body constitutions are considered to be the indicators of Nutritional status, physical and psychological activities, and General Immunity of an individual.

According to Siddha philosophy every human fits into any one of the Udaliyal/YakkaiIlakkanam (YI) among the three basic body constitutions such as Vali, Azhal and Aiyam. He briefed the nature of each Udaliyal/ YakkaiIlakkanam (YI) in relation to their inbuilt immune status as follows, Vali type of body constitution have low immune status, stressful and confused state of mind and are poorly nourished, despite their intake being nutritive. Azhal type of body constitution having 3 folds of high immunity status compared with Vali, moderate stressed mind, and moderate level of nutritional absorption from foods. Aiyam type of body constitution have high immunity, strong will power, and good nutritional status. In his presentation he added scientific support to the philosophy of YakkaiIlakkanam quoting the results of a study conducted to assess the immune and nutritional status of quarantine people and COVID-19 positive patients in Tirupati using Siddha Yakkai Ilakkanam (YI) Tool (https://www.siddhayitool.com/).

He also explained that the patients in the District COVID Care Center- Tirupati, $43 \%$ are found to have Vali type of body constitution, 17\% were Azhal and 40\% were of Aiyam. Of the quarantined population, $43 \%$ of were under Vali, 21.4\% were from Azhal and 35.7\% were from Aiyam. He concluded that from the above observation, Prevention and prophylactic management in Siddha system is directly related to the nature of the body constitution of a person. So, medicines selected on the basis of individual Yakkai Ilakkanam for COVID19 could be a better way of Prevention and Prophylactic measure through Siddha System of medicine.

Manickavasagam. R, M.D(S), Research Officer (Siddha), Scientist-I and In-charge, Siddha Clinical Research Unit, Safdarjung Hospital, New Delhi.

Manickavasagam elaborated the "Rationale of Siddha medicine Kabasuram and Kabasura kudineer in COVID-19". Before getting into the topic, he gave a brief introduction about origin, nature of spread of COVID 19, that has affected 28.0 million people and caused 908, 500 deaths until Oct-2020. He explained the common symptoms of COVID 19 and its resemblance with symptoms of Kabasuram that has been quoted in Siddha literatures like Therayar Yamaga Venba, Theran Karisal, Sura Vagadam and Yugi Vaithya Sinthamani. Table 1 shows the details how COVID-19 symptoms could be analogized with Kaba Suram

He explained about the scientific studies that were conducted on ingredients of KSK showing Anti Pyretic, Anti-viral, Immuno Modulator, Anti-Microbial, Anti Asthmatic, Antitussive, Expectorant, Astringent, Refrigerant activities. Also, he quoted studies that explored the antiviral activity of KSK specifically against spike proteins of novel coronavirus.

Natarajan. S, M.D(s) Research Officer (Siddha), Scientist-I, Head, Department of Clinical Research, Siddha Central Research Institute, Chennai, Tamil Nadu

Natarajan explained the clinical trial titled "The efficacy of Siddha Medicine, KSK compared to Vitamin $\mathrm{C}$ and Zinc (CZ) supplementation in the management of asymptomatic COVID-19 cases". He conducted (Randomized Controlled Trial) RCT to know the efficacy of the intervention of KSK in one arm (30 patients) and Vitamin C and Zinc (30 patients) clearly by investigating the viral load of patients involved in that study before and after drug intervention. The intervention was said to be a standalone intervention which indicates one group of patients only received KSK and another group received only Vitamin $\mathrm{C}$ and Zinc. The study was registered in Clinical Trial Registry of India (CTRI). Laboratory investigations were recorded only in the Indian Council for Medical Research (ICMR) empaneled laboratory. The study results revealed that the Siddha drug KSK intervention plays a crucial role in decreasing the viral load among COVID-19 asymptomatic patients. This research work was published in an indexed peerreviewed journal, he concluded that though this research finding was conducted in a small number of patients, the identified impact of KSK in decreasing viral load can help us with a lead for conducting further clinical trials.

Sankara Raj P, M.D (s), Asst. Medical Officer (Siddha), Govt. General Hospital, Theni, Govt. of Tamil Nadu.

Sankara Raj clearly explained his clinical research work on COVID 19 patients in Government hospital in Theni, that patients (30 patients) in one arm received only Zinc and Vitamin $\mathrm{C}$ and, and another arm received KSK \& Zinc and Vitamin C. Immuno Modulator activity was assessed using Flow cytometry. Expression of cytokines IL10, IL6, IL2, TNF Alpha and ILF gamma were quantitatively measured. He strongly confirmed that the drug KSK has some beneficial effect in the treatment 
of COVID 19. The last panel exclusively discussed the in the District COVID Care Centers of Tamil Nadu. experiences that happened during the research conducted

Table 1. COVID-19 Symptoms analog with Siddha literatures

\begin{tabular}{|c|c|}
\hline Siddha terminology & COVID-19 Symptoms \\
\hline Suram & Fever \\
\hline Udal Veluththal & $\begin{array}{c}\text { Discoloration of Body Parts } \\
\text { (Mugam,Fingers,Toes and Whole Body) }\end{array}$ \\
\hline KozhalKakkal & Cough \\
\hline Mel Moochu & Difficulty in Breath/Shortness of Breath \\
\hline MarbuUzhaithal & Chest Pain \\
\hline AdikadiKalaiththuPothal & Tiredness \\
\hline VaaiKularal & Loss of Speech \\
\hline Thayakam & Confusion \\
\hline MaarbilKozhaiKattiKodnu kuru kuruoli & Advance Stage of Infections \\
\hline AdikadiKalithal & Diarrhoea \\
\hline "Ayiranayananmeiyaniyinirame" -- TheranKarisal & Discoloration of the body parts \\
\hline "MugamathuVelikkum" & Discoloration of Face \\
\hline "MugamVelluthuKaanal" - Sura Vagadam & Discoloration of Face \\
\hline "Manthaabamaarnothalirumalilaippu" & Chest Pain,Cough,Difficulty in Breath \\
\hline "VaaiThuvarMathameurusiyillai" & Loss of Taste/Smell \\
\hline $\begin{array}{l}\text { "Sinthabamitarunonthumeen mooch } \\
\text { chaathal,Thinavetuthal" - YugiVaithyaSinthami }\end{array}$ & Sore Throat,Difficulty in Breath,Skin rashes \\
\hline "Nakkumunnunaurisiillai" & loss of taste \\
\hline "Maar ThondaiNokum" & Chest Pain \& Sore Throat \\
\hline "Makaudalthinavu" & Skin Rashes \\
\hline "Mananthuvalum" & Confusion \\
\hline "Veiyasuranth thana lirumal" & Fever \& Cough \\
\hline "Kurukuruththalathisaarangkalazhumaba" & Diarrhoea \\
\hline "PeelaiVazhiyumirukannum" - Sura Vagadam & Eye symptoms \\
\hline
\end{tabular}

Thillaivanan S, M.D(s), Asst. Medical Officer, Government Hospital, Pernambut, Vellore District, Tamil Nadu

He elaborated the history and origin of Siddha system of medicine and also explained the role of Siddha medicine in this pandemic. He gave an introduction about the Covid Care Center, exclusively established to provide Siddha treatment to the mild to moderate COVID-19 patients, initiated by the Tamil Nadu government in most of the districts in Tamil Nadu. He explained the functioning of COVID Care Centre (CCC) in Vellore that treated a greater number of COVID-19 positive patients with Siddha medicines, next to Chennai. This center is a model for its unique treatment protocol with Siddha medicines as per the guidelines of AYUSH ministry, Government of India. The District Collector of Vellore took essential steps for a Siddha treatment center with great interest and focused objective.

He explained the treatment with Siddha medicine was initiated on $10^{\text {th }}$ July 2020 . The patients were treated by Siddha medicine for improving quality of health and to reduce the various signs and symptoms of the COVID-19 disease. Nearly 3000 patients were treated by Siddha 
medicine at this center. Patients were treated with proper consent and feedback was collected over the course of the medicine. The feedback shows patients were relieved from signs and symptoms of the COVID disease. $\mathrm{He}$ added that the crucial challenge, during quarantine days, is to manage the patient's psychological stress. So the Siddha medical officers who were present in the duty at CCC instructed the patients to carry out Agathiyar Asanam techniques, Thirumoolar Breathing exercises, Thirumoolar meditation techniques, Siddha Varmam Therapy, etc. He listed the prescribed Siddha medicines for asymptomatic, mild to moderate COVID positive patients as follows,

1. Kapa Sura Kudineer - $60 \mathrm{ml}$ twice daily before meals

2. Amukkara Chooranam Tablet - 2 tablets thrice daily, after meals

3. ThalisathyVadagam - 2 tablets thrice daily, chewable, after meals

4. BramananthaBairava tablet - 1 or 2 tablets twice daily after meals

5. Adathodaimanapagu - $10 \mathrm{ml}$ twice daily with warm water.

He also explained the importance of SIddha based diet regimen which consists of Ginger (zingiber officinale), Amla (Phyllanthus emblica), Cucumber (Cucumis sativus), Garlic (Allium sativum), Onion (Allium cepa), Carrot (Daucus carota), Beetroot (Beta vulgaris), and an immune-boosting salad daily.

Sankar Ananth P, M.D(s), Medical officer, ALMA Siddha Care Centre, Madurai, Tamil Nadu

He explained his experience in the COVID treatment of more than 750 cases were treated with the Siddha medicines during this period. Among them, 400 patients were enrolled in the trial for the phase I clinical trial conducted in the Madurai COVID Care Centre. With the guidance of the Director General, CCRS, Chennai, Prof. Dr. Pitchia Kumar, State Drug Licensing Authority and Dr. Thanigavelan, Research Head, ALMA Siddha Care Centre the study was conducted at Madurai by
Dr. Sankar Ananth and Dr. Senthil, Dr. Jagathish Babu had done the field work of collecting data and distribution of KSK to the public. 200 completed case sheets and proper informed consents were collected for the trial. With this experience they expanded the distribution of COVID kit to Chennai and Tirunelveli also. In Chennai along with the CCRS more than 870 COVID positive cases were treated.

Also, he explained one case study of a 27 year old Auto driver who met with an accident and had fracture in the wrist joint with ligament injury. Due to his being COVID positive the surgery was postponed, after he was treated with Siddha medicines he turned negative in 5 days. Finally, he concluded his presentation that Integration of Siddha and Biomedicine becomes the boon in this COVID Pandemic period to prevent the spread and reduce the mortality rate.

\section{Conclusion}

Dr. Samraj. K, the organizing secretory of this web conference, summarized the speakers' Research and clinical experience on COVID-19 pandemic. This web conference provided three take home information to the participants, which were,

1. Traditional medicines like Siddha medicine needing more clinical trials and experience sharing platforms, which will be crucial for the development of Siddha clinician and Researchers.

2. The significant outcomes were noted in both clinical practice and research of the Siddha standalone as well as integrative management on COVID-19

3. Central Council for Research in Siddha (CCRS), Directorate of Indian Medicine and Homeopathy (DIM\&H), Government of Tamil Nadu, contributed a lot in Research and clinical service in COVID-19 pandemic.

Finally, the web conference was concluded with the vote of thanks by Dr. S. Radha, Consultant, SCRU, Tirupati. 